submitted to the

Lawrence Livermore Laboratory

Livermore, CA 94550

\title{
Rayleigh-Taylor Instability in Compressible Fluids
}

For the Period

1 October 1989 - 30 September 1990

Principal Investigator: B. Sturtevant

\section{Graduate Aeronautical Laboratories \\ Califomia Institute of Technology \\ Pasadena, CA 91125}

November 5, 1990

\section{DISCLAIMER}

This report was prepared as an account of work sponsored by an agency of the United States United States Government nor any agency thereof, nor any of their Government. Neither the United States Government nor any agency theres liability or responsiemployees, makes any warranty, express or implied, or assumformation, apparatus, product, or bility for the accuracy, completeness, or usefulness of any inforivately owned rights. Referprocess disclosed, or represents that its use would not infringe privately ow service by trade name, trademark, ence herein to any specific commercial product, process, or service by trade name, trademark, manufacturer, or otherwise does not necessarily $\mathrm{c}^{-n s t i t u t e}$ or imply its endorsere the views mendation, or favoring by the United States Govinment or any agency thereof The of the and opinions of authors expressed herein do not

United States Governmeni or any áginicy thereof. 
DISC IAIMIER

Work performed under the atespices of the L:.s. Department of Energy by Iawrence livermere National Iaboratory under contract number W-7405-EN(;-48.

This document was prepared as an account of nork sponsored by an agency of the I'nited States (jovernment. Neither the (Inited States (iovernment nor the l niversity of California nor any of their employees, makes any naranty. espress or implied, or assumes any legal liabilie or respocesibility for the accuracy, completeness, or usefilness of any information, apparatus, product, or precess ilisclosed, or represents that its use would not infringe privately owned rights. Reference herein to any specific commercial products, process, or service by trade name, trademark, manufacturer, or ofherwise, does not necessarily constitute or imply its endorsenent, recemenendation, or favoring by the I nited States ciovernment or the Iniversity of California. The views and opinions of authors expressed herein do not necessarily state or reflect those of the l loited States Government or the I niversity of California, and shall not be used for advertising or product endorsement purposes. 


\section{Rayleigh-Taylor Instability in Compressible Fluids}

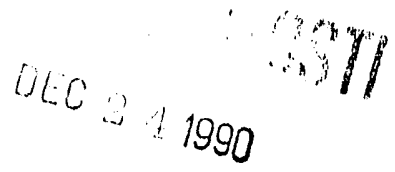

\section{Introduction}

This is a report of the progress during the past year of the shock-tube study of the RichtmyerMeshkov instability, initiated under the sponsorship of the Lawrence Livermore National Laboratory in September, 1982. The purpose of this research program, as stated in the original proposal, is:

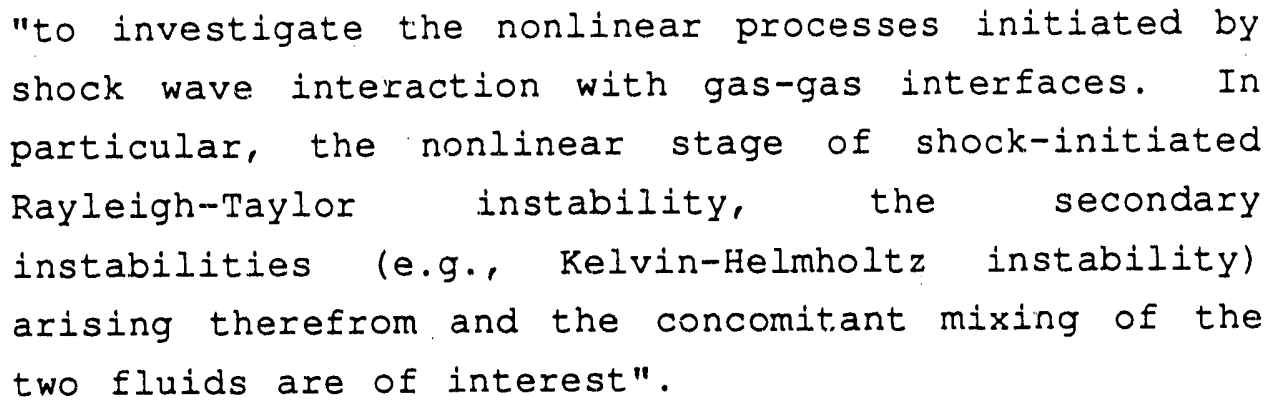

Last year's report presented an extensive data set documenting the growth of the 'visible thickness' induced by normal shock acceleration of (i) initially diffused and (ii) membrane-formed interfaces. Smooth interfaces of type (i) were studied in the initially flat configuration ('multi-scale') and with quasi-sinusoidal ('single-scale') distortions initially imposed, while type (ii) interfaces were initially flat. Thus, comparison was not made with the original Meshkov shock tube experiments. The visible thickness was measured by high-speed motion picture and still schlieren photography. During the present year the configuration of the experimental set-up has been modified to substitute an X-ray imaging system (which had been designed, procured and fabricated during the previous year) for the schlieren flow visualization system. A major part of the year was spent in an exhaustive investigation of the generation and quantitative interpretation of $\mathrm{X}$-ray images using the Hewlett-Packard Faxitron $\mathrm{X}$-ray source.

Preliminary experiments have been carried out on some representative cases of shock-excited Richtmyer-Meshkov instability in order to compare quantitative $\mathrm{X}$-ray results with the previous schlieren flow visualization results obtained in this laboratory. It has been shown that the X-ray technique is sufficiently sensitive to, for example, clearly indicate wall jets that wcre discovered in the schlieren experiments. Late-time mushroom-like plumes, the details of which had not been well resolved by the schlieren method, have been exhibited by the X-ray images. Early indications are that the actual growth of 'single-scale' disturbances on thick interfaces (type (i)) is smaller than the 'visible thickness' measurements had indicated. 


\section{Progress Report}

\section{I. X-Ray System and Calibration.}

In order to substitute the X-ray system for the schlieren system, it was necessary to modify the test section to replace the $38 \mathrm{~mm}$ thick glass windows with $1 \mathrm{~mm}$ thick carbon filament plates to minimize absorption of the X-ray beam. The carton filament plates, which are flush with the inner walls of the test section, are supported against the internal pressure of the shock-compressed test gas by an egg-crate aluminum structure. The grid spacing of the stiffening assemblies are different: the one further away from the X-ray source is coarser to account for the parallax effect due to the conical spreading of the $\mathrm{X}$-ray beam. Thus the shadow of the front grid falls on that of the rear one and only one pattern is seen in the X-ray image.

During each experiment the X-ray film is sandwiched between a pair of fluorescent screens contained in an aluminum cassette (with a cardboard front). The cassette is mounted on the outer wall of the test section with a jig. The $\mathrm{X}$-ray source is located $1.83 \mathrm{~m}$ away from the film, its axis coinciding with the center line of the test section.

Considerable effort was devoted to an exhaustive investigation of the generation and quantitative interpretation of X-ray images using the flash $\mathrm{X}$-ray source. The source has now been characterized and a method for correcting for source nonuniformity and lack of repeatability has been developed. Elements of the X-ray measurement procedure which have been investigated and finalized during the past year include:

1. The optimum combination of X-ray film and phosphorescent screen has been adopted. Our colleagues at CEA-Vaujours, who previously, after an investigation of available X-ray sources, had followed our lead in selecting the Hewlett-Packard scurce, have now also adopted our filmscren combination, thus, in a sense, confirming its superiority over other alternatives.

2. The optimum separation between source and film, to obtain maximum contrast on the film has been selected. Investigation of a technique for pre-exposing the film did not yield enhanced contrast, and so was abandoned.

3. Film developing time and temperature were optimized.

4. It was found to be preferable to perform densitometry in our own laboratory using a CCD camera and light box, than to send out X-ray negatives for analysis by an independent laboratory (e.g., JPL). Performing the task in house gives us control, flexibility and economy, all crucially important for exploratory research.

5. The response of a Sony Model AVC-D1 8-bit CCD camera used for densitometry is linear in the range $50-150$ output counts. Averaging over 25 digitizations of a single negative yields a $10 \%$ noine level in a $376 \times 480$ pixel field. 
6. Optical density is determined by taking a local pixel-to-pixel ratio between an image of the light box and that of a shock tube run.

7. The method is calibrated by comparing the optical density of a calibration cell filled with xenon at different pressures with the optical density of known thicknesses of aluminum.

8. Averaging xenon densities in columns of about 20 pixels width on $\mathrm{X}$-ray negatives of the shock tube flow reduces the noise level from the $10 \%$ cited above to $1 \%$.

9. Typical mass densities for xenon in these experiments are 0 (pure air), 5.5 (atmospheric pressure) and $19.0 \mathrm{~kg} \mathrm{~m}^{-3}$ (reflected shock region for a $M_{s}=1.52$ incident shock in air). Typical CCD camera count (Pixel), optical density (OD) and equivalent thickness of aluminum (Al) are as follows:

\begin{tabular}{crlr}
$\begin{array}{c}\text { Density } \\
\left(\mathrm{kg} \mathrm{m}^{-3}\right)\end{array}$ & Pixel & OD & $\begin{array}{c}\text { Al } \\
(\mathrm{mm})\end{array}$ \\
\hline 0 & 40 & 0.7 & 0 \\
5.5 & 95 & 0.25 & 7 \\
19.0 & 120 & 0.17 & 22
\end{tabular}

Thus over the full range of expected densities the system yields about $61 / 2$ bit resolution. However, not all of the above results are understood. In particular, the correspondence between xenon density and aluminum thickness does not correspond to what would be expected from the relative values of tabulated absorption coefficients. The uncertainty arises from the fact that we do not know what spectrum of X-rays is emitted by the source. The results imply that the aluminum is absorbing with a larger effective absorption coefficient (averaged over the spectrum of the source) than would be expected from the measured effective xenon absorption coefficient, an unlikely, if not impossible, behavior, since the $\mathrm{Al}$ is irradiated with the same spectrum as the Xe. These uncertainties require further work to establish the errors inherent in the data reduction procedure.

10. The Hewlett-Packard source, oriented in the way it was first installed in our shock tube laboratory, yields a dome-shaped intensity pattem on the $\mathrm{X}$-ray negative. Variations in the vertical direction are smaller and variable, but measurable, and are approximately linear. Thus the method for correcting for beam nonuniformity depends on the orientation of the source. Experiments seeking a more uniform orientation of the source were inconclusive, perhaps because temporal nonrepeatability of the intensity of the source renders attempts to obtain quantitative data fruitless. Thus a method was developed for correcting each image with information about intensity and nonuniformity obtained in each run. Until we understand the cause of the spatial nonuniformity of the source we will not be able to adequately limit the estimate of ermr induced 
by it.

11. Using the above techniques, it has been determined that the thin metal plate used to separate air from xenon prior to the continuous interface experiments leaks, and a certain amount of air mixes with the xenon in the test region prior to a run. Methods will be developed for detecting and correcting for this initial nonuniformity in experimental conditions.

In summary, to achieve a quantitative procedure for performing $\mathrm{X}$-ray densitometry on high- $\mathrm{Z}$ gases, a relation between the density of the gas and the known thickness of a reference material included in each X-ray image (presently aluminum, but perhaps more appropriately a wedge of the test gas at high pressure) is obtained by the following procedure:

1. exposure of $\mathrm{X}$-ray negatives containing the images of regions of xenon at known density (generated by filling the calibration cell to measured pressures),

2. normalization of each negative to account for X-ray beam spatial non-uniformities,

3. evaluation of the optical density of the xenon regions and the aluminum wedges,

4. elimination of the optical density to obtain a direct relationship between $\mathrm{Xe}$ density and $\mathrm{Al}$ thickness.

A result of one such trial is the calibration curve of figure 1.

The development of the X-ray diagnostic method is in large part complete and we can now turn our attention to its application to studies of the shock-induced Richtmyer-Meshkov instability.

\subsection{X-ray Visualization of Xenon Mixing at an Interface.}

A fa'se-color photograph of the X-ray image of a flow generated by a $M_{s}=1.32$ shock wave propagating across a plane interface is shown in figure 2 . The picture was taken only $200 \mu \mathrm{s}$ after the shock had interacted with the interface. The color indicates the optical density of the image, white being low (high density xenon), yellow being high (zero xenon concentration). Dominating the photograph is the grid structure of the egg-crate supports for the carbon fiber windows. The interface is in the second cell from the top, and is the plane horizontal transition from yellow above through red to blue below. The sharp transition from blue-white to blue in the third cell from the top is the downward-propagating shock wave. On the right of the test section is the 22 step aluminum wedge used for calibration. After applying the calibration curve of figure 1 to this photograph, the xenon density profile of figure 3 results. The long horizontal spikes in figure 3 are the egg-crate grids, and the transition from zero deisity to $-3.2 \mathrm{~kg} \mathrm{~m}^{-3}$ is the interface. The shock transition can be seen just above the bottom grid. The density gradient that is superimposed on the above-mentioned transitions suggests that prior to this rur air leaked across the metal plate dividing the air from the xenon causing a stable stratification of the xenon. 
Figure 4 shows an air/Xe interface $2.5 \mathrm{~ms}$ after being accelerated by a $M_{s}=1.32$ shock wave. The xenon was exposed to air for $1.2 \mathrm{~s}$ after plate retraction, prior to shock arrival. This timing yields the 'single-scale' configuration depicted in the photograph. The growth of the perturbations observed at this time has been significant; before and just after shock arrival they are not measurable in either the $\mathrm{X}$-ray or schlieren images. Also visible on the shock tube walls just below the interface, especially at the left edge of the image, are the 'wall jets' discovered by Brouillette, the neglect of which we have suggested may be one cause for the disagreement between the growth rates we observe and those reported in earlier experiments at other laboratories.

\subsection{Growth Rate of Single-Scale Perturbations.}

The late-time amplitude of the perturbations in figure 4 is considerably smaller than that observed with the previous schlieren pictures of air/ $\mathrm{SF}_{6}$ interfaces at comparable times (figure 5 ). In fact, the schlieren photograph in figure 5 shows distinct plumes, typical of the nonlinear growth at later times. Whether this disagreement between the two experiments is due to different behavior of xenon and $\mathrm{SF}_{6}$. or to considerable difference in the sensitivity of the two methods, remains to be investigated. It should be noted that the plumes occur on the low-density side of the interface, where X-ray absorption is small. The signal to noise ratio at the optical density values of pure air indicates that xenon can be successfully imaged at densities as low as $\sim 0.2 \mathrm{~kg} \mathrm{~m}^{-3}$. On the other hand, schlieren is sensitive to density gradient, and so may image plumes where the $\mathrm{X}$-rays can not.

A series of X-ray pictures similar to that of figure 4 has been used to obtain a tentative estimate of the growth rate of the interface perturbations. A method comparable to that used by Brouillette for the schlieren experiments has been used. In particular, the separation of the crests and troughs has been measured at the visible upper and lower boundaries of the interface, and the results averaged to yield one value. Brouillette used an approach in which the average crest was determined from the upper edge of the plume and the lower boundary of the interface, carefully distinguishing the interface from the boundary layer effect which is the cause of the most prominent apparent lower boundary in figure 5 . The results are presented in figure 6 , which is a reproduction of one of Brouillette's figures with the new data added. The circles are the schlieren data for the air/SF ${ }_{6}$ interface and the crosses are the $\mathrm{X}$-ray data for the air/Xe interface. The more recent data are seen to show a much lower growth rate. After a larger set of $\mathrm{X}$-ray images has been obtained, the growth rates will be measured using definitions of single-scale amplitude and interface thickness based on integrals of the density distribution.

As described in last year's report (and by Brouillette), a different configuration of perturbations can be obtained if less time is allowed between plate retraction and shock arrival. In figure 7 the delay was only $0.5 \mathrm{~s}$, with the consequence that the perturbations are much larger near the left wall, to which the metal plate retracts. Indeed, though this configuration has not been used for quantitative measurements (the negative being particularly non-uniform as it can be seen even from the spatially-corrected color image), it can be argued that it provides both a quasi-single-scale behavior on the left and a multi-scale on the right. In this case the perturbations on the left have grown to such a large amplitude that plume 
formation can be seen quite clearly in the X-ray image (figure 7). This picture corresponds quite closely to a schlieren photo of an air/SF 6 interface taken by Brouillette (figure 8 ), including the wall vortices seen on both the right and left walls. The optical density gradient directed from the xenon to the air region in the $\mathrm{X}$-ray image and the dark region representing the interface in the schlieren image are both an indication of the local gas density gradient. (The major difterence between the two figures is that there is one less plume in the air/Xe case than in the air/SF 6 case.)

\subsection{Investigations of Shock Reflection from a Compliant End Wall.}

During a meeting with Livermore scientists last year the question arose whether a silicone rubber plug that was used to adjust the length of the shock tube could have an effect on the strength of the reflected shock wave due to the lower acoustic impedance of rubber than steel. The velocity of the reflection of a $M_{s}=1.6$ incident shock wave was measured and compared against 1-D gasdynamics predictions: the two values were $324 \mathrm{~m} / \mathrm{s}$ and $325 \mathrm{~m} / \mathrm{s}$, respectively.

\section{Summary of Accomplishments}

1. By obtaining, for the first time, X-ray images of shock-compressed xenon, it has been shown that $\mathrm{X}$-ray densitometry with high- $\mathrm{Z}$ gases is sufficiently sensitive to resolve all the important features of the shock-wave generated Richtmyer-Meshkov instability occurring in conventional shock tubes, including heavy-gas plumes occurring in late-stage single-scale growth and wall jets and vortices discovered in our earlier experiments.

2. A calibration procedure for converting $X$-ray negatives into 2 dimensional images of xenon density has been developed and tested. Accuracy is such that quantitative measurements of Richtmyer-Meshkov mixing can now be made. However, inadequate understanding of the absorption cocfficients of substances used in the calibration, of the spectrum of the X-ray source, of its repeatability, and of leakage past the interface during run preparation require further consideration.

3. It has been shown by comparing the visual thickness of air/SF $\mathrm{S}_{6}$ interfaces measurer in earlier schlieren experiments with the thickness of air/Xe interfaces defined in a comparab.:- way but obtained from X-ray images, that the X-ray-determined thicknesses appear to be substantially thinner than the schlieren thicknesses. This tentative result will be checked in the near future by carrying out schlieren flow-visualization experiments on the air/Xe configuration.

4. It has been shown that methods used to vary the test-section length in the present studies of Richtmyer-Meshkov mixing do not affect the properties of reflected shock waves. 
Calibration

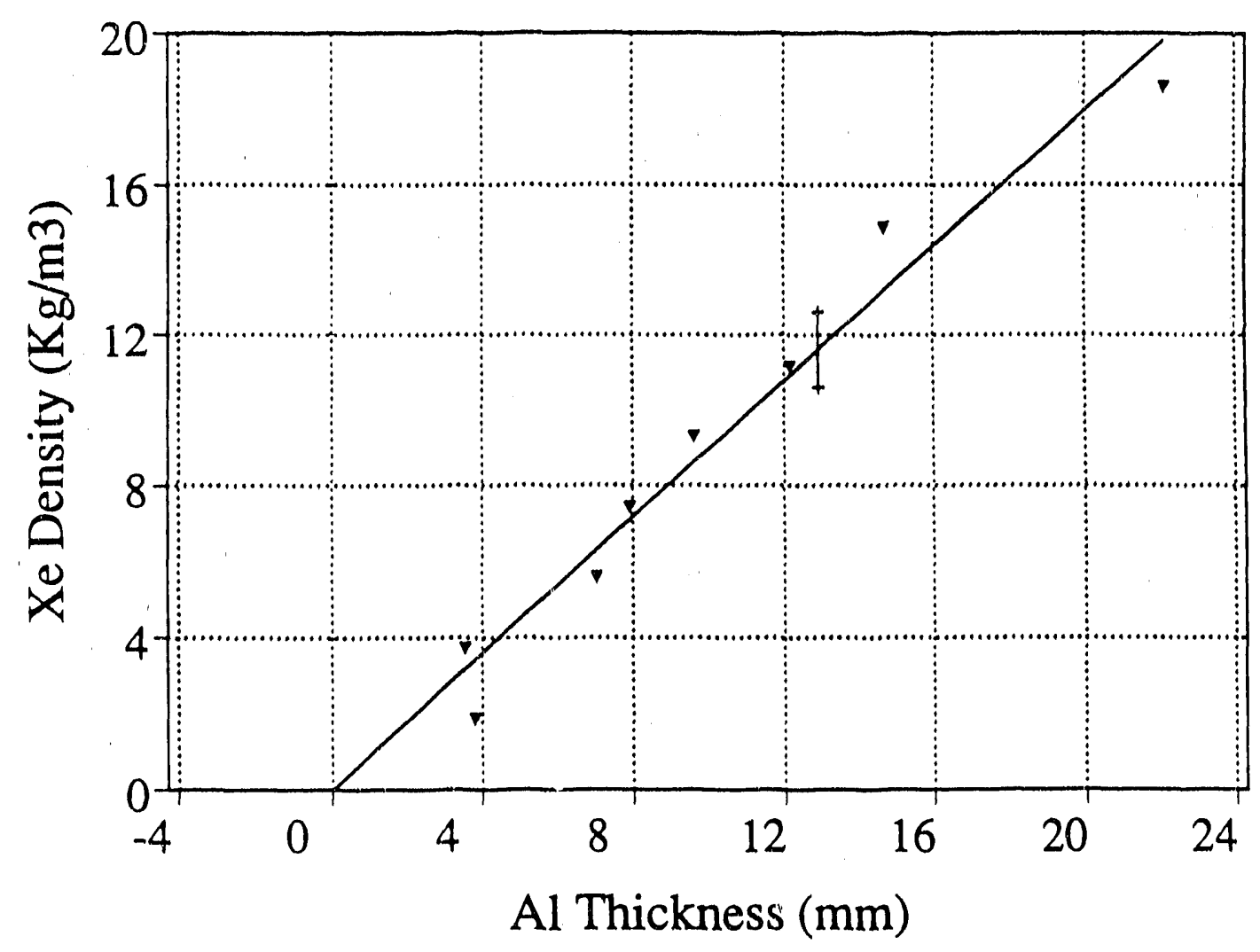

Figure 1. Calibration line for xenon density. 


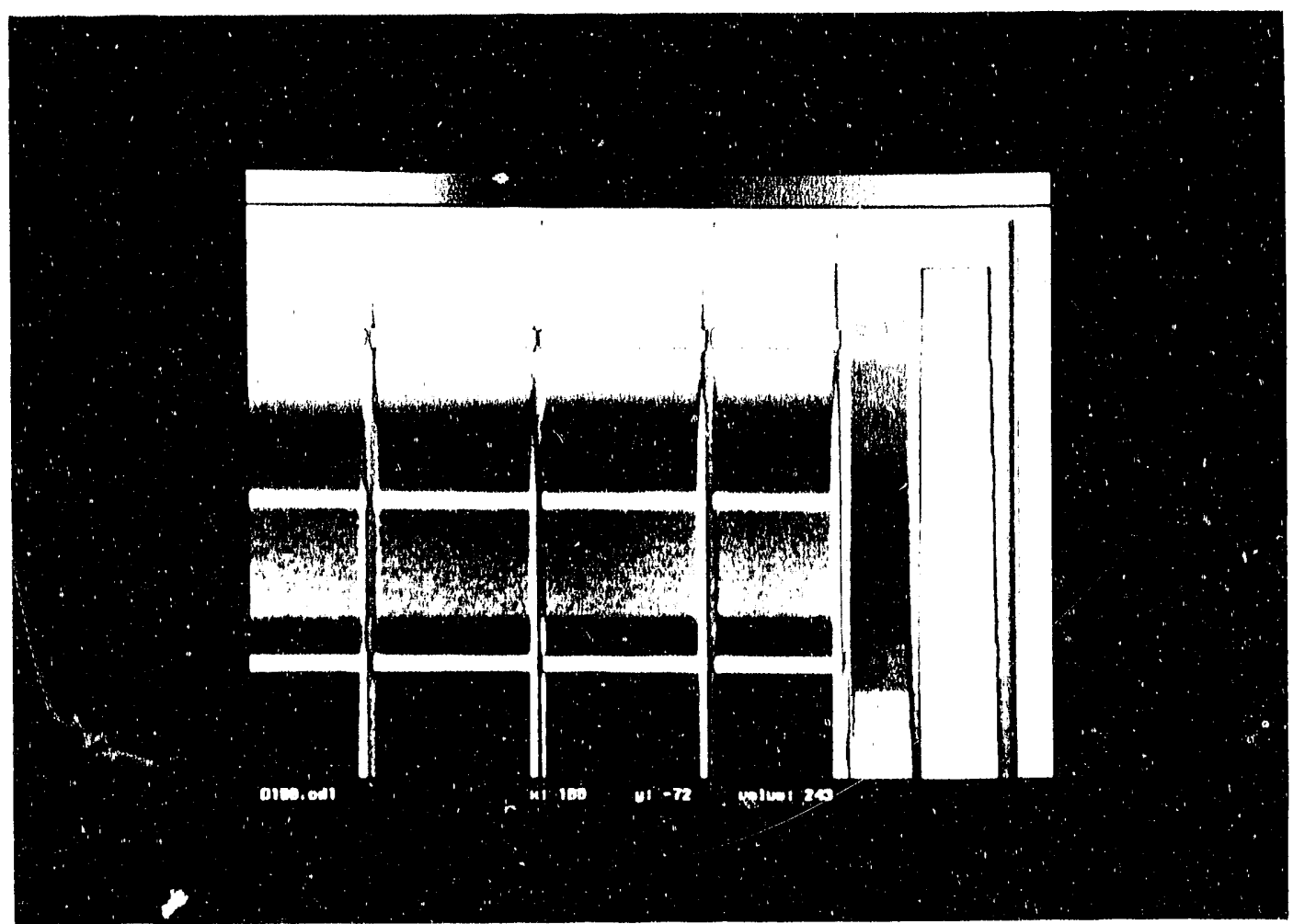

ligere 2. False color image of $X$-ray photo of an air/Xe interface $2(X)$ fes after interaction with a $M_{s}:-$ 1.32. sherek walve.

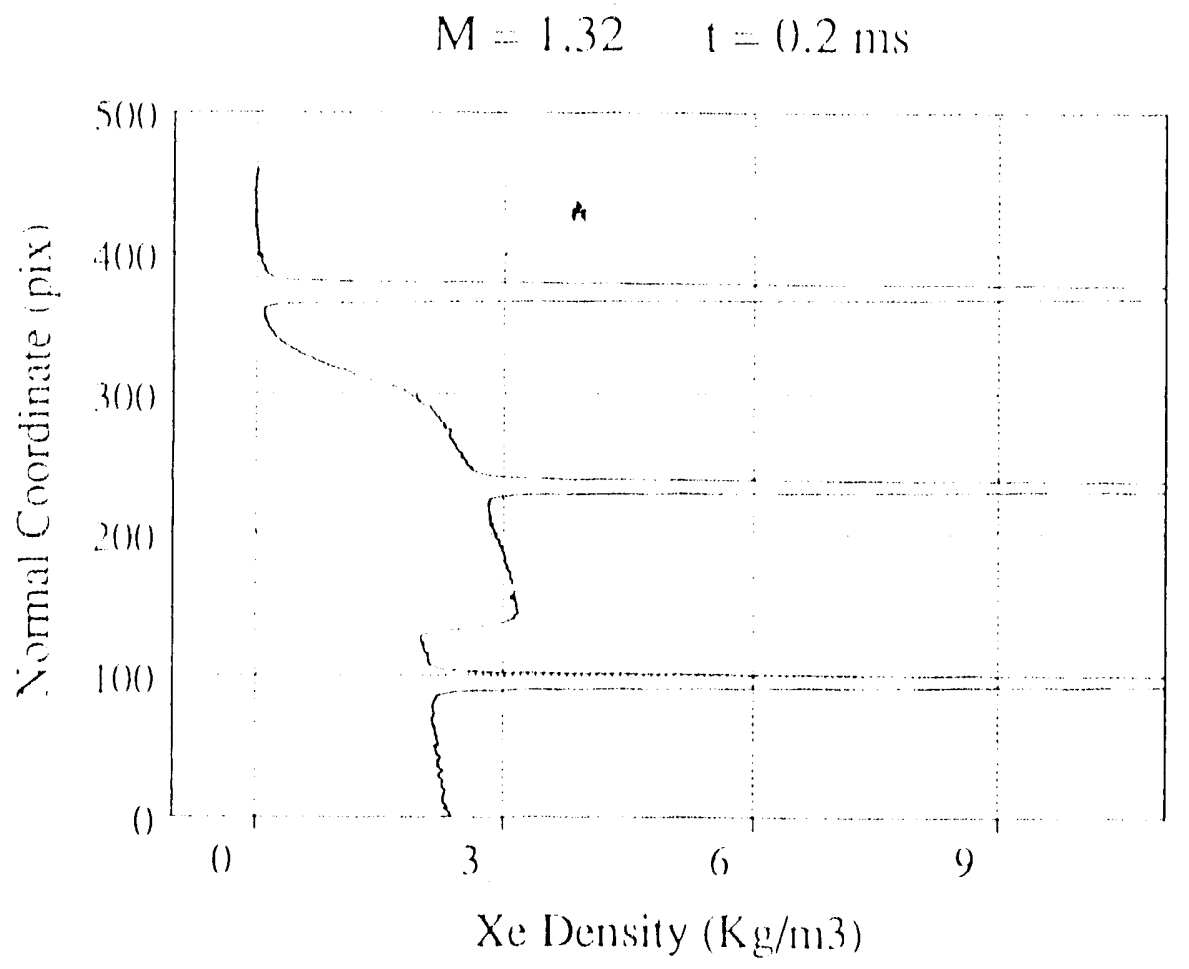

Piggure 3. Xenon density protile from the inage of tigure 2. 
.8.

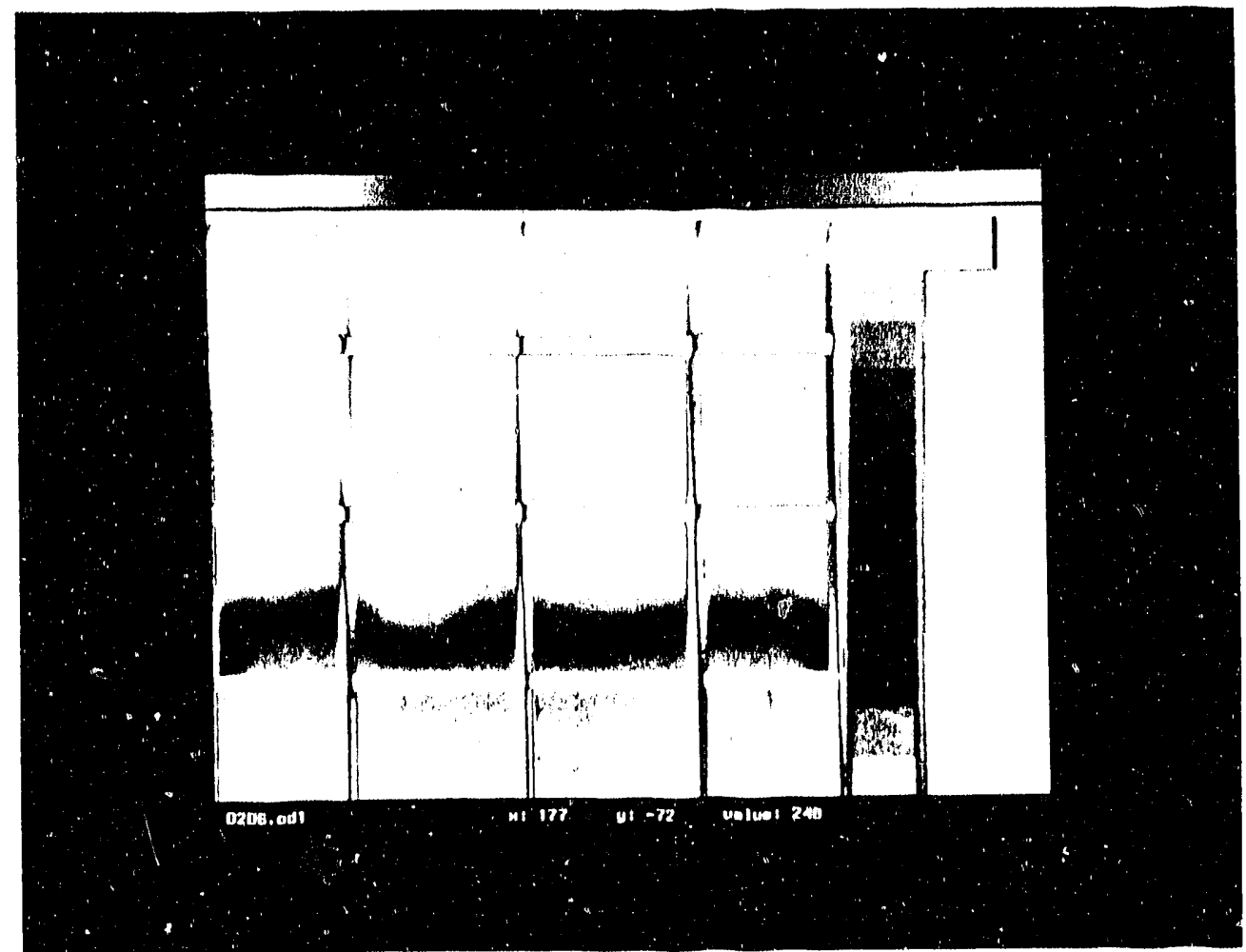

Figgure 4. False color image of optical density from an $X$-ray photo of the single scale pattern on an air/Xe interface $2.5 \mathrm{~ms}$ after interaction with a $M_{s}=1.32$ shoek wave.

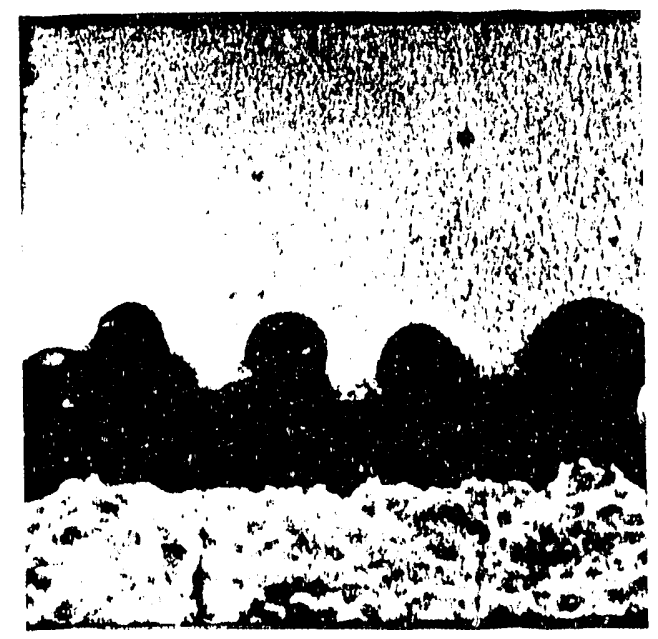

Figure 5. Schlieren photogiaph of the single scale pattern on an air/SF, interface $1.7 \mathrm{~ms}$ after inleraction with a $M_{s}=1.32$ shock wave. 


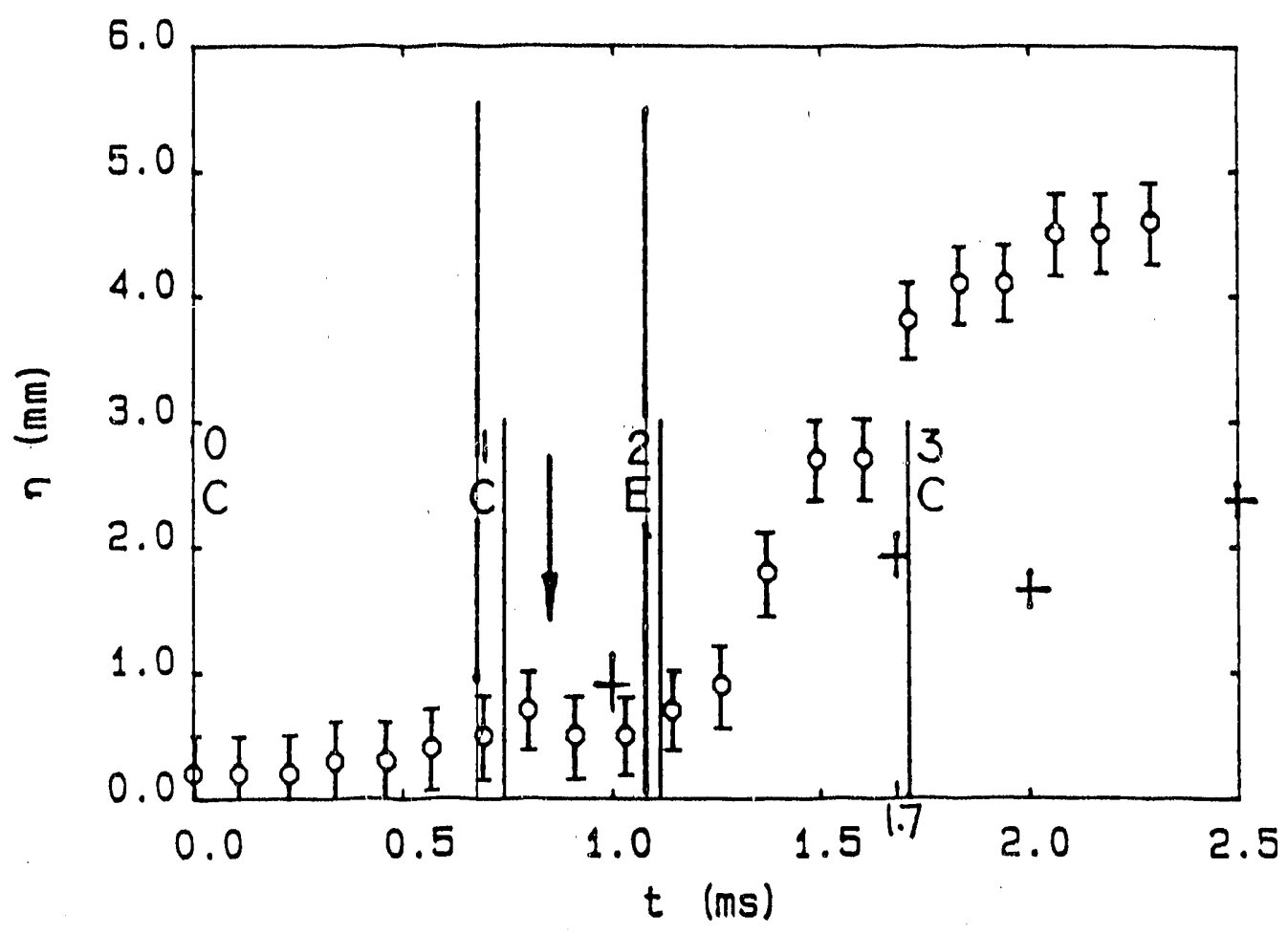

Figure 6. Amplitude of single scale perturbations on an air/ $\mathrm{SF}_{6}$ interface (circles) compared with the amplitude of an air/Xe interface (crosses). 


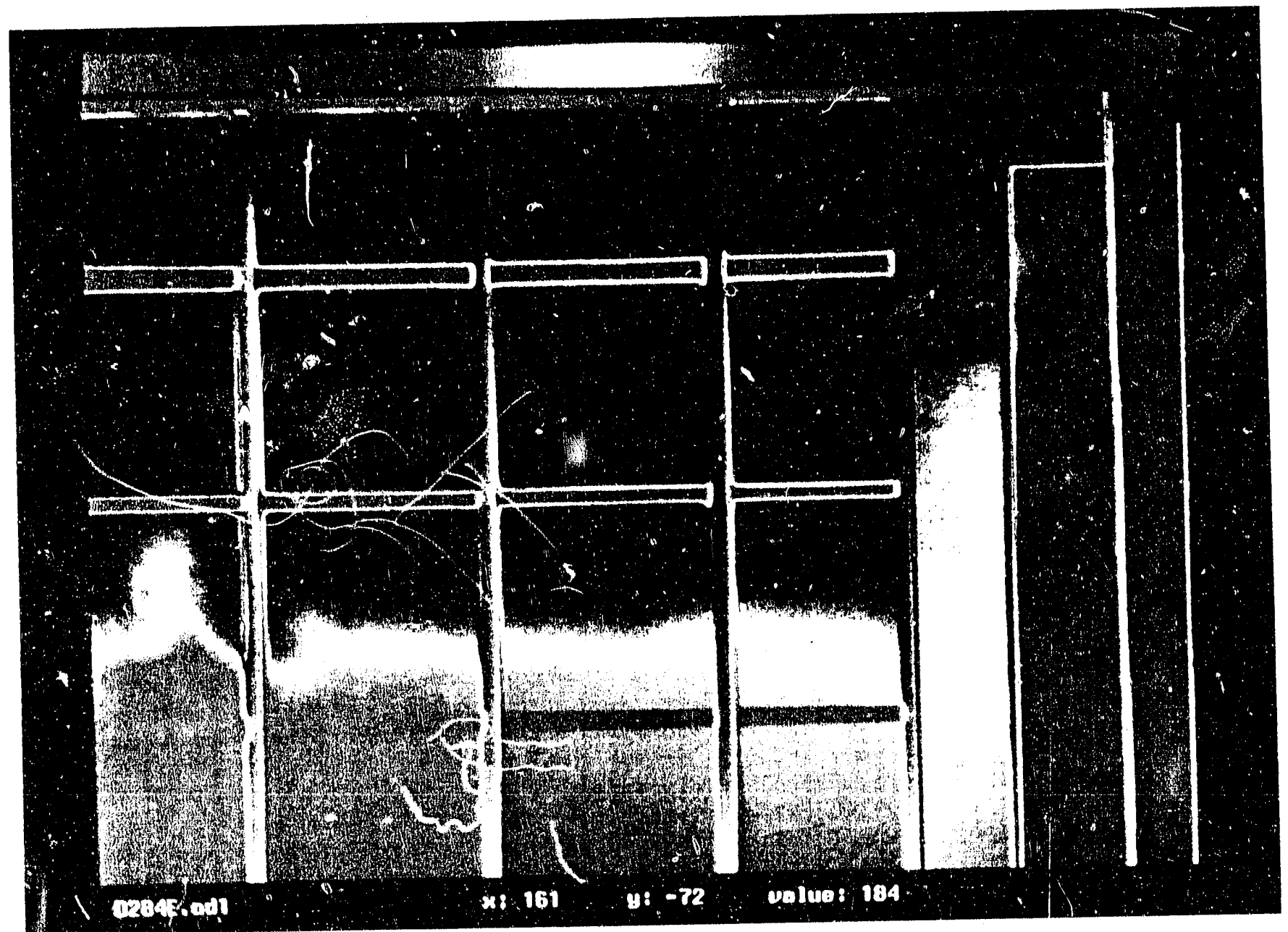

1.ipure 7. False color image of optical density from X-ray photo of short-delay single scale prattern on aii, is incertace $25 \mathrm{~ms}$ alter interaction with a $M_{s}=1.32$ shock wave.

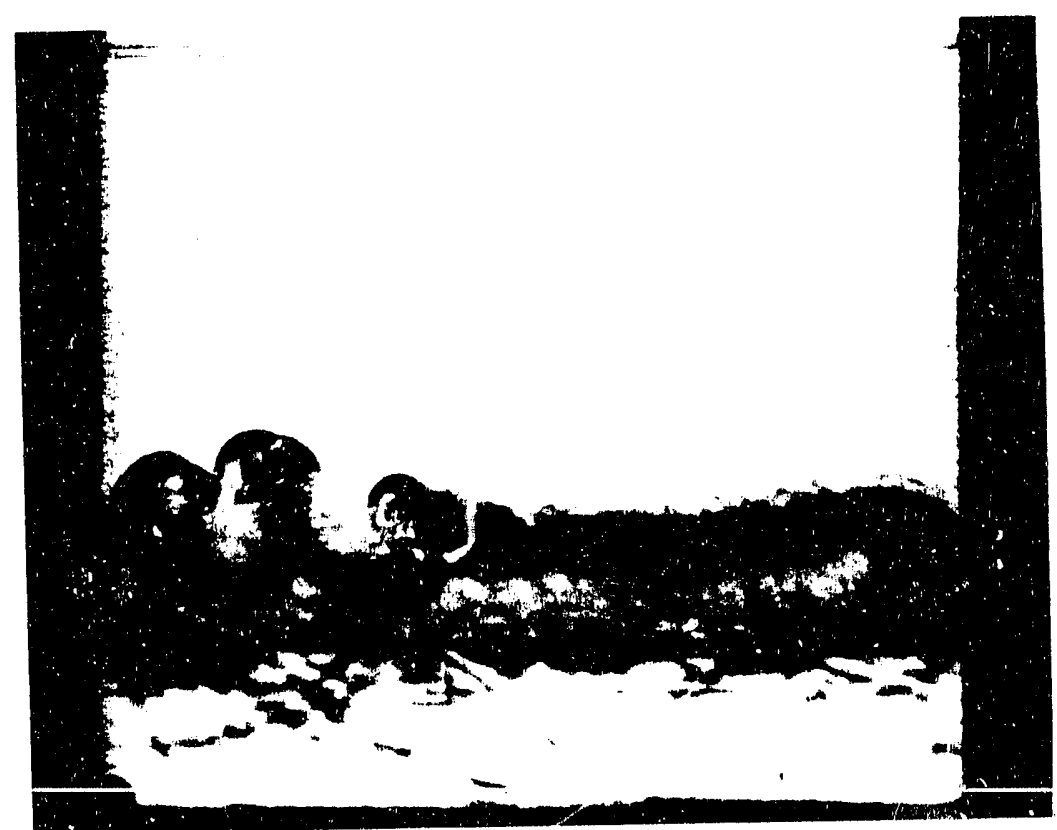

figure 8 . Schlieren photograph of the short delayy single scale pattern on an air/SF, imlerface 1.6 .3 ms atter interation with a $M_{s}=1.32$ shock wave. For comparison with figure 7 . 
-END-

DATE FILMED

$1 / 5 /$ 
